AGH DRILLING, OIL, GAS • Vol. 33 • No. $1 \cdot 2016$

http://dx.doi.org/10.7494/drill.2016.33.1.105

\author{
Piotr Kosowski*, Michał Kuk*
}

\title{
COST ANALYSIS OF GEOLOGICAL SEQUESTRATION OF $\mathrm{CO}_{2}$ **
}

\section{INTRODUCTION}

The relation between anthropogenic greenhouse gas emissions and global warming on Earth is recognized by a large part of scientists, but has not been finally confirmed, and still is controversial. Opponents of this theory point out, among others, the fact that the cyclic climate change and related changes in temperature and carbon dioxide content in the atmosphere occurred in the past and, therefore, present changes are a natural process and independent of human activities [7, 21].

However, the question remains open whether anthropogenic emissions do not interfere the natural process of climate change, because since the industrial revolution, the carbon dioxide content in the atmosphere has increased by about $31 \%$, reaching in 2000 the highest value of about 400000 years [9]

Therefore, the problem of greenhouse gas emissions, above all carbon dioxide, which is produced mainly in the processes of combustion of fossil fuels is one of the most important and of highest interest in issues related to the protection of the environment [23]. Particular care is taken to reduce emissions and ways of utilization of already emitted $\mathrm{CO}_{2}$ [27].

In many countries over the years have been carried out activities related to the reduction of greenhouse gas emissions, and its limitations can be done in several ways, e.g by: reforestation, renewable or nuclear energy and the implementation process of carbon sequestration [26, 27].

However, despite many opportunities to reduce $\mathrm{CO}_{2}$ emissions, the effectiveness so far and the number of projects to prevent the penetration of anthropogenic carbon

* AGH University of Science and Technology, Faculty of Drilling, Oil and Gas, Krakow, Poland

** The research leading to these results has received funding from the Polish-Norwegian Research Programme operated by the National Centre for Research and Development under the Norwegian Financial Mechanism 2009-2014 in the frame of Project Contract No. Pol-Nor/235294/99/2014 
dioxide in the atmosphere is small. If no measures are taken to significantly reduce emissions, some experts predict an increase in the average temperature of the Earth in 100 years from about $1.4^{\circ} \mathrm{C}$ to $5.8^{\circ} \mathrm{C}$, and the effect of increase in the average temperature of the Earth may be a drastic change in climate, related to adverse weather conditions such as hurricanes or floods [8].

In order to reduce $\mathrm{CO}_{2}$ emissions is used, among other things, carbon sequestration, understood as a process of separation and capture of $\mathrm{CO}_{2}$ from the flue gas stream. Sequestration may take place in the following ways [28]:

- physical (geological storage),

- chemical (mineral sequestration of carbon dioxide),

- biological (reforestation, biomass).

While sequestration methods can be divided into:

- direct - catching carbon dioxide before it discharges to atmosphere),

- indirect - involving the removal of carbon dioxide from the atmosphere.

As part of direct sequestration we distinguish among others: storage in aquifers, storage in exploited oil and natural gas deposits, storage in coal seams, storage in the oceans. In contrast, indirect sequestration include: reforestation, the use of carbon dioxide as an activator of algae growth, factors enhancing plant growth [23, 28].

The article specifically mentions factors affecting the cost of geological sequestration, which consists capture carbon dioxide before its discharge into the atmosphere, transport to a storage location and its subsequent injection into a suitable geological structures.

Additional benefit when used in the process of hydrocarbon, is possibility to increase exhaustion coefficient and gaining further extraction. The origins of geological sequestration date back to 1952 , when technology for injection of liquid $\mathrm{CO}_{2}$ into reservoirs was patented.

Geological storage consists of several stages: separation of carbon dioxide, transport, compression and injection as well as monitoring behavior of $\mathrm{CO}_{2}$ in geological structure. However, due to the high costs of geological sequestration, it is not currently the most popular method used to reduce $\mathrm{CO}_{2}$ emissions. The amount of carbon dioxide, which has been crowded in geological structures is low, and moreover most of the $\mathrm{CO}_{2}$ used to this type of project is derived from natural sources [23].

\section{THE CHOICE OF $\mathrm{CO}_{2}$ SOURCES}

Important point in the planning process of carbon sequestration is a choice of the gas source (emitter). This is an important step as if not chosen correctly, it may influence the costs of sequestration process. When selecting the emitter of carbon dioxide should be taken into account factors such as the amount of gas produced and its concentration in the exhaust gas, the location of the emitter (the distance from the target site injection of gas) and the composition of exhaust gases. The selected source should emit exhaust gases with a relatively high carbon dioxide content. 
However, due to the amount and availability, the most popular source of emissions of $\mathrm{CO}_{2}$ are fossil fuel power plants. Among the power plants usually chosen, are those with power over $1 \mathrm{MW}$, a minimum power, for which it can be considered the construction of a plant for separation of carbon dioxide from the flue gases [16].

According to Benson S.M. [1], average project injecting carbon dioxide into oil fields requires an inlay around $4 \mathrm{Mt} / \mathrm{year}$, while most fossil fuel power plants, have between 500-1000 MW power [21], what reflects into production of carbon dioxide at a level of $6 \mathrm{Mt} / \mathrm{year}$ to $8 \mathrm{MT} / \mathrm{year}$, and this is a sufficient value to connect the underground storage with advanced methods of extraction (CCS-EOR) [9].

Another important criterion based on which separation technology is chosen, is the composition of exhaust gas, which depends on, among others, combustion technology and fuel used [4]. In addition, the distance between the source of carbon dioxide and its place of injection should be considered [17].

\section{SEPARATION OF $\mathrm{CO}_{2}$}

Separation is an important step in the process of sequestration. Most of the literature indicates that the cost of separation of carbon dioxide from flue gases is between $50 \%$ and even $75 \%$ of the sequestration process [12], and is dependent on $[2,9,27]$ :

- kind of emitter,

- content of exhaust,

- amount of exhaust,

- technology of $\mathrm{CO}_{2}$ separation.

Taking into account available technologies and the possibility of separation, the most expensive source from which we can separate carbon dioxide is the petrochemical industry. The second place in terms of costs of obtaining carbon dioxide, are power plants. However, due to their large number and volume of production of $\mathrm{CO}_{2}$ they are the best source of obtaining this gas.

The cost of capturing in this case ranges from $35 \$ / \mathrm{tCO}_{2}$ to $40 \$ / \mathrm{tCO}_{2}$. A similar carbon dioxide capture expense $\left(25 \$ / \mathrm{tCO}_{2}\right)$ has separation during the steel production. By far, the best source for purely commercial reasons, is the chemical industry. With a small amount $\left(8 \$ / \mathrm{tCO}_{2}-9 \$ / \mathrm{tCO}_{2}\right)$ carbon dioxide can be obtained. Summary of average costs is shown in Figure 1.

There are three main approaches to carbon dioxide separation from combustion processes:

- post-combustion method,

- pre-combustion method,

- oxy-fuel combustion method.

Post-combustion capturing of $\mathrm{CO}_{2}$, or separation of carbon dioxide from the flue gas, is the most expensive, and therefore the least profitable. The cost per ton of separated carbon dioxide is from $\$ 80$ to $\$ 107$. 


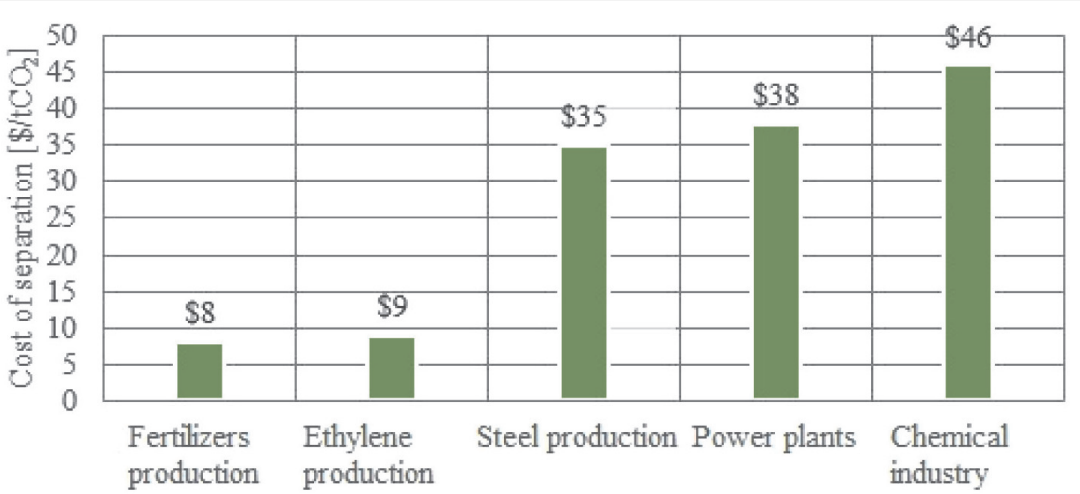

Source of emission

Fig. 1. Average cost of carbon dioxide separation depending on the source of emission [8-10]

In contrast, pre-combustion separation process, wherein the capture of $\mathrm{CO}_{2}$ occurs prior to combustion. An alternative method to the mentioned above, is the use of combustion in pure oxygen (oxy-combustion). With this process, the exhaust gases contain mainly carbon dioxide and water vapor [14].

The costs of separation of a tonne of $\mathrm{CO}_{2}$ depending on the method, are as follows (Fig. 2) [11]:

- post-combustion: $\$ 80-\$ 107$,

- pre-combustion: $\$ 55-\$ 67$,

- oxy-fuel combustion: $\$ 52-\$ 78$.

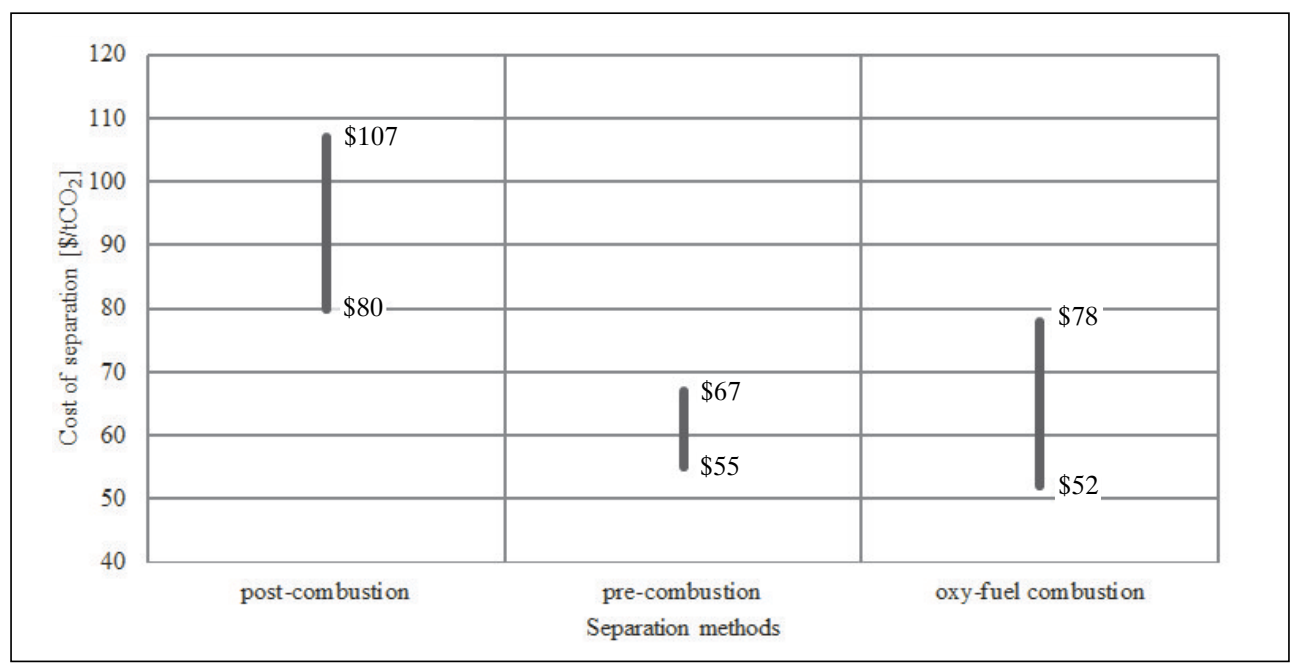

Fig. 2. The range of costs of $\mathrm{CO}_{2}$ separation from combustion process [11] 
As can be seen from the above examples, the cost of separation depends on many factors, and its range varies from a few to a few hundred dollars in extreme cases, which means that each project must undergo an individual assessment of costs.

\section{TRANSPORT}

Another factor influencing the overall cost of the process of carbon sequestration is to transport from a source to a place of injection, and its cost depends on, among others $[3,8,9,27]$ :

- distance from the source (most important factor),

- way of transport (pipeline, tanker, transport wheel),

- assumed flow,

- terrain (rivers, mountains, frozen ground),

- infrastructure encountered on the path of the pipeline,

- legal regulations.

The most common methods of transmission are: the transport of gas by a pipeline or sea transport - using tankers. The costs of carbon dioxide pipeline transport consist of such factors as the volume (diameter) of the pipe and the characteristics of the where it will be located [10].

The cost of pipeline transport ranges from $0.20 \$ / \mathrm{tCO}_{2}$ to $40 \$ / \mathrm{tCO}_{2}$, but in most of the literature it is in the range of $6 \$ / \mathrm{tCO}_{2}$ to $8 \$ / \mathrm{CO}_{2}$ [4]. The cost of transport by sea is closely related to the distance of gas transferring, but its price is affected by additional factors such as $[3,21]$ :

- capacity available for the medium,

- costs of uploading and downloading system,

- cost of liquefaction of carbon dioxide.

A detailed influence of factors on the total cost of tanker transport is shown in Figure 3 .

Another way to deliver $\mathrm{CO}_{2}$ is a road transport. This way carbon dioxide can be transported with a use of professional road tanker. In this case, the cost of carbon dioxide transport, at a distance of about $100 \mathrm{~km}$ is $\$ 16$, although in the case of larger volumes of gas and large distances, price sharply increases. [14].

Figure 4 shows the cost of transport of $\mathrm{CO}_{2}$ depending on the distance between the emitter and the place of injection. It can be noticed that up to the distance of about $1500 \mathrm{~km}$ it pays to transport carbon dioxide by a pipeline. However, above this value, if possible, must be considered sea transport, due to the high costs associated with the infrastructure that is essential for the proper operation of the pipeline [15]. 
One problem is maintaining the pressure within the pipeline. The longer the pipeline is, the more losses it generates, and thus it requires more devices that will raise the pressure of carbon dioxide flow [17, 20].

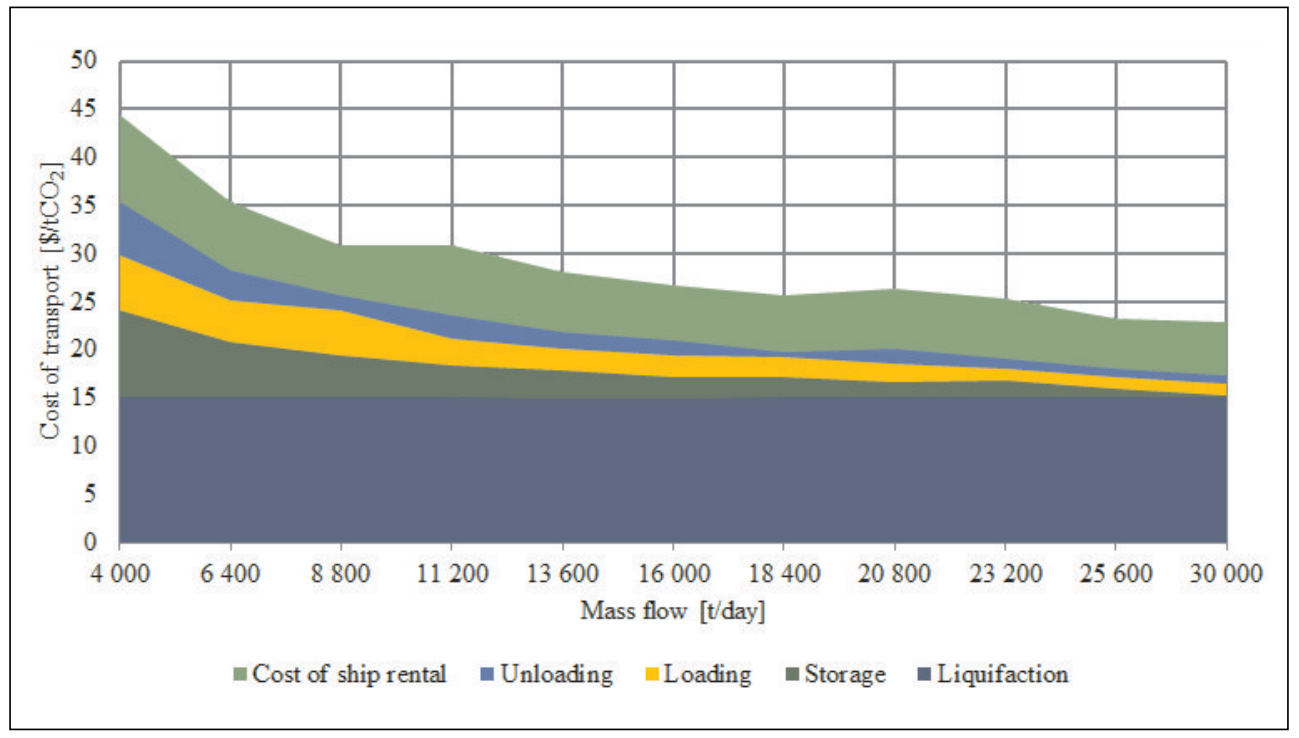

Fig. 3. Factors influencing the total cost of the sea transport [21]

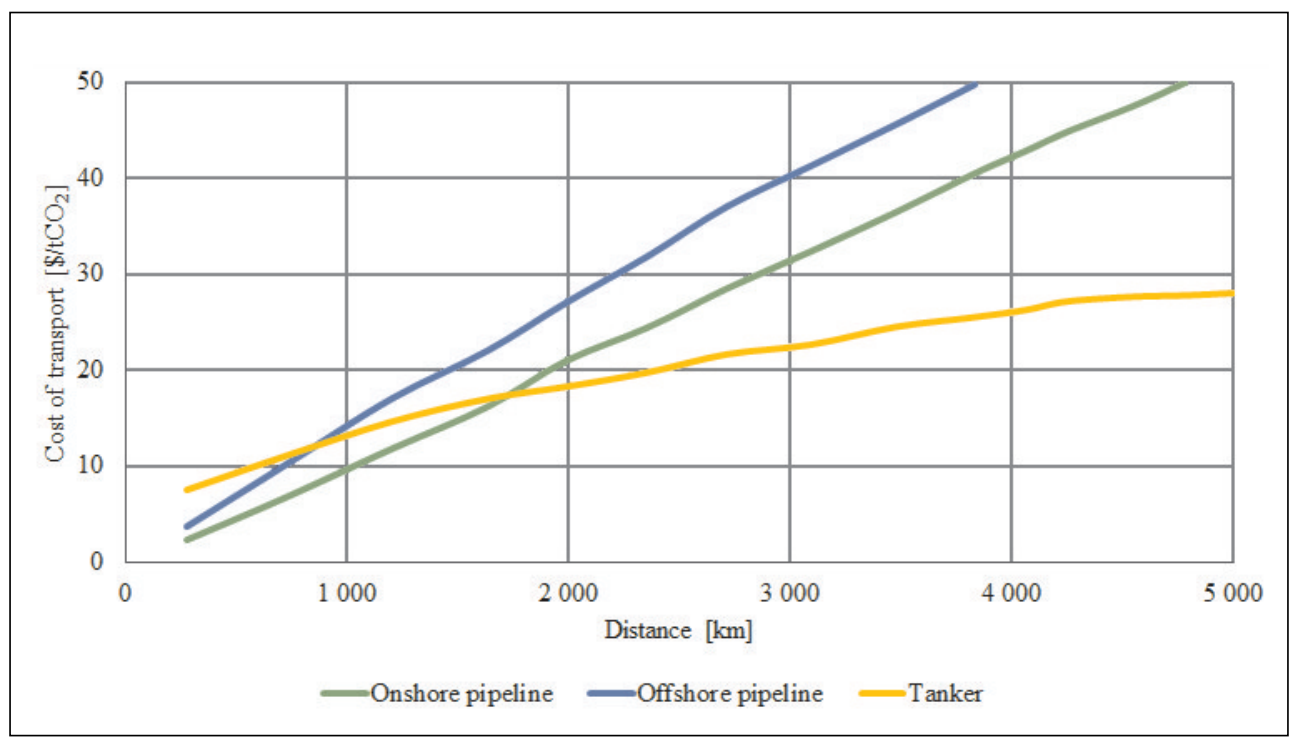

Fig. 4. Cost of transport depending on distance (Texas) [3] 


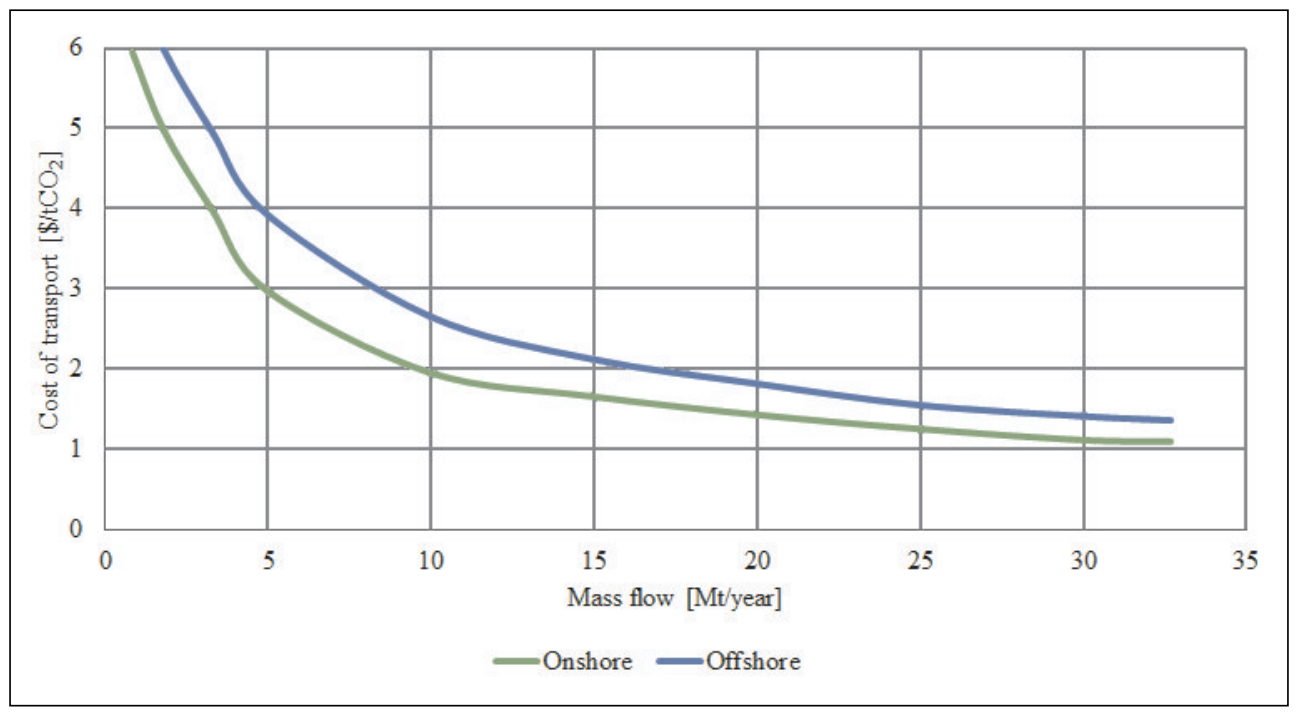

Fig. 5. The cost of transport depending on the mass flow of the medium on land and sea [3]

The cost of transport decreases with increasing amount of carbon dioxide transfer (Fig. 5).

\section{INJECTION}

The last important factor influencing the cost of sequestration of $\mathrm{CO}_{2}$ is injection and monitoring. This step consists of injection pressurized gas into the deposit in order to store it in a reservoir rock, or to obtain additional energy, which will increase production of hydrocarbons (in case of applying the method CCS EOR).

Injection of gases (including carbon dioxide) is a very effective method of EOR (enhanced oil recovery) for light oil and of average weight, and its use can increase the rate of exhaustion from $10 \%$ to $30 \%[19,14]$.

Following factors influence the cost of carbon dioxide injection [8]:

- location of injection well,

- depth of injection,

- average temperature in reservoir rock,

- injection rate,

- the amount of injected $\mathrm{CO}_{2}$,

- the permeability of the reservoir rock.

Additionally, the cost of the injection affects the amount of $\mathrm{CO}_{2}$. This dependency is shown in Figure 6. 


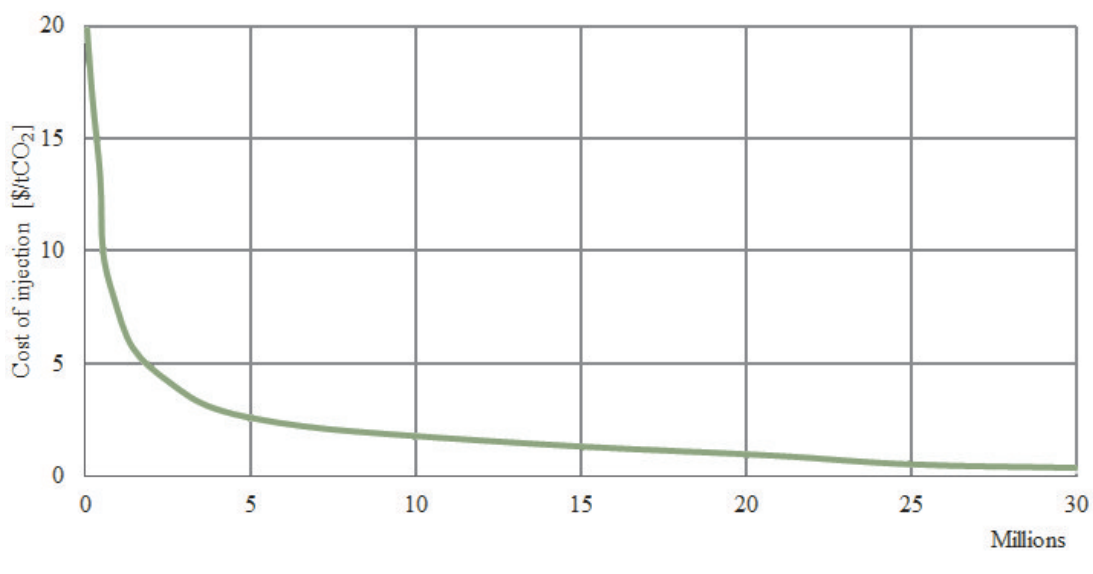

Amount of $\mathrm{CO}_{2}$ captured [t/year]

Fig. 6. The cost of injection depending on the amount of $\mathrm{CO}_{2}$ captured [13]

Another factor influencing the cost of injection is the depth of structures where gas is injected (Fig. 7).

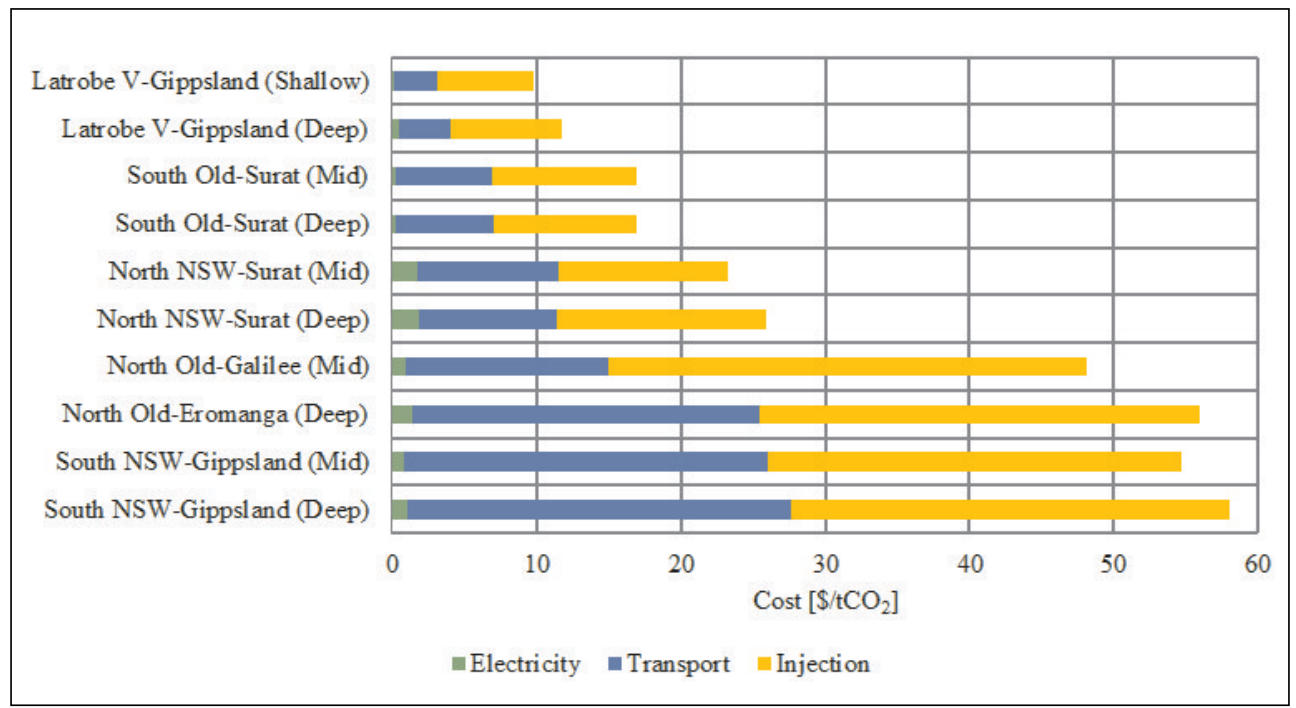

Fig. 7. The cost of various factors influencing the total price of sequestration process for individual deposits located in Australia [5]

In majority of cases shown on the chart, the cost of injection to the structures located at shallow depths with the cost of $\mathrm{CO}_{2}$ injection into deep rock formations was 
compared. The cost ranges from few to several dollars, which means that depending on factors such as depth or type of rock formation it may sharply change [18]. Usually, the costs of injection include costs associated with the monitoring of the injected gas in order to avoid unwanted migration. This process is required for the storage of gas in underground rock formations, and its cost is relatively small and amounts to about $0.2 \$ / \mathrm{tCO}_{2}[3,21]$.

Other cost is typical for the storage of carbon dioxide under the seabed. In this case, the main determining factor for injection is the distance that must be overcame by a ship or the location of the pipeline on the seabed. The cost is approx. $14 \$ / \mathrm{tCO}_{2}$ for the ship, which must cover a distance of every $100 \mathrm{~km}$ and a $16 \$ / \mathrm{tCO}_{2}$ for the pipeline with a length of $500 \mathrm{~km}[13]$.

\section{SUMMARY}

Carbon sequestration is a multi-level and costly process. The share costs of various stages that influence this process, based on the example of projects carried out in the United States, is shown in Figure 8.

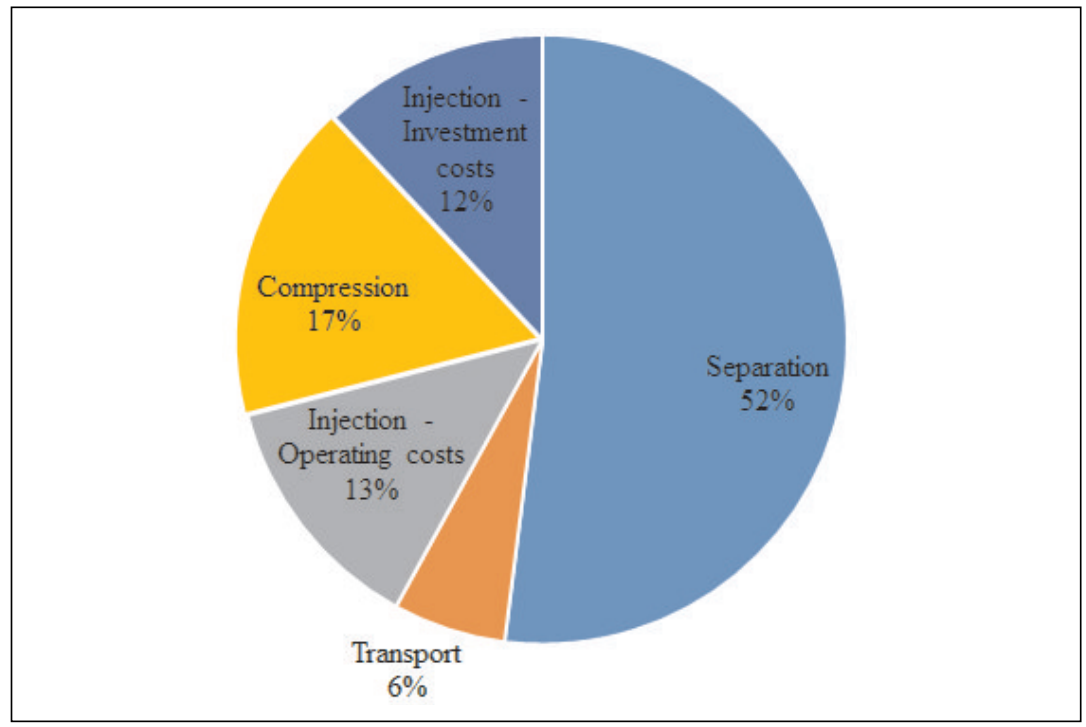

Fig. 8. Influence of the cost of individual factors of sequestration process on its expense [6]

The separation and capturing of $\mathrm{CO}_{2}$ is the most expensive step in the process of geological sequestration, and its cost is from 50 to $75 \%$ of the total cost of underground $\mathrm{CO}_{2}$ storage, wherein varies considerably depending on the type of emitter, a technology in which $\mathrm{CO}_{2}$ is formed and separation method. 
The next stage, which has a significant impact on the cost of sequestration is transport of $\mathrm{CO}_{2}$. The cost of providing gas to the site depends on many factors, such as: distance, means of transport, the number of transported medium, terrain and infrastructure on the path of the pipeline as well as regulations and specifications. Transport costs along with compression for projects carried out in the US represent on average $23 \%$ of the costs of sequestration.

Accordingly, the important issue is also a proper choice of $\mathrm{CO}_{2}$ emitter, as in the case of badly selected gas source, it may too much influence the cost of the process sequestration. When selecting the emitter of carbon dioxide, should be taken into account factors such as the amount of gas produced and its concentration in the exhaust gas, the location of the emitter (the distance from the target site injection of gas) and the composition of exhaust gases.

The last stage, which is discussed in the article is injection and monitoring. The following factors influence the cost of carbon dioxide injection: location of injection well, depth of storage structure, reservoir characteristics, environmental conditions, injection rate and the total amount of $\mathrm{CO}_{2}$ to be injected.

In summary, the geological sequestration is an expensive undertaking, which may considerably affect the economic efficiency of technological processes, which result in generated carbon dioxide. It is difficult, therefore, to count on a positive attitude of emitters, unless the implementation of projects of this type will be forced on them by a system of fees, penalties and limits associated with the issue or be encouraged by the system of subsidy and incentives.

One of the ways for cost-effective carbon sequestration is to combine it with advanced methods of oil extraction where injected $\mathrm{CO}_{2}$ allows for a significant increase in exhaustion coefficient of the deposit, and additional income from oil extraction allows to finance the process of sequestration.

\section{REFERENCES}

[1] Benson S. M., Berkeley L.: Monitoring carbon dioxide sequestration in deep geological formations for inventory verification and carbon credits. Society of Petroleum Engineers, 2006.

[2] Bode S., Jung M.: Carbon dioxide capture and storage - liability for non-permanence under the UNFCCC. Int Environ Agreements, 2006.

[3] Bruce B.: Clean coal engineering technology (Chapter 10. $\mathrm{CO}_{2}$ Capture and Storage). Elsevier, 2011, pp. 485-509.

[4] Burton M., Bryant S. L.: Eliminating buoyant migration of sequestered $\mathrm{CO}_{2}$ through surface dissolution: Implementation costs and technical challenges. Society of Petroleum Engineers, 2007.

[5] Cinar Y., Allinson W.G., Neal P.R., Hou W.: Cost of $\mathrm{CO}_{2}$ transport and injection in Australia. Society of Petroleum Engineers, 2010. 
[6] Damena K., Bergenb A. F., Galec J., Lysend E.: Identification of early opportunities for $\mathrm{CO}_{2}$ sequestration - worldwide screening for $\mathrm{CO}_{2}$-EOR and $\mathrm{CO}_{2}$ ECBM projects. Energy, 2005.

[7] Dubiński J., Wachowicz J., Koteras A.: Podziemne składowanie dwutlenku węgla możliwości wykorzystania technologii CCS $w$ polskich uwarunkowaniach. Główny Instytut Górnictwa, 2010.

[8] Gaspar A.T.F.S., Lima G.A.C., Suslick S.B.: $\mathrm{CO}_{2}$ capture and storage in mature oil reservoir: Physical description, EOR and economic valuation of a case of a Brazilian mature field. Society of Petroleum Engineers, 2005.

[9] Gaspar A.T.F.S., Suslick S.B., Ferreira D.F., Lima G.A.C.: Economic evaluation of oil production project with EOR: $\mathrm{CO}_{2}$ sequestration in depleted oil field, Society of Petroleum Engineers, 2005.

[10] Gaspar A.T.F.S., Suslick S.B., Ferreira D.F., Lima G.A.C.: Enhanced Oil Recovery with $\mathrm{CO}_{2}$ Sequestration: A Feasibility Study of a Brazilian Mature Oilfield. Society of Petroleum Engineers, 2005.

[11] Gurjar B.R., Ojha C.S.P., Surampalli R., Zhang T.C., Walvekar P.P.: Carbon capture and storage: An overview. American Society of Civil Engineers, 2015.

[12] Han F.X., Lindner J.S., Wang C.: Making carbon sequestration a paying proposition. Springer, 2007.

[13] Hasan M.M.F., First E.L., Boukouvala F., Floudas C.A.: A multi-scale framework for $\mathrm{CO}_{2}$ capture, utilization, and sequestration: CCUS and CCU. Computers and Chemical Engineering, 2015.

[14] Herzog H., Golomb D.: Carbon capture and storage from fossil fuel use. Massachusetts Institute of Technology Cambridge, 2004.

[15] Holloway S.: Sequestration - the underground storage of carbon dioxide. British Geological Survey, 2008.

[16] Johnsson F., Kjarstad J., Odenberger M.: The importance of $\mathrm{CO}_{2}$ capture and storage - A geopolitical discussion. Thermal Science, 2012.

[17] Kang K., Seo Y., Chang D., Kang S.G., Huh C.: Estimation of co ${ }_{2}$ transport costs in south Korea using a techno-economic model. Energies, 2015.

[18] Kapteijn P., Oil M., Kutscha E., Perron J., Cordova R.: A breakthrough oxy-fuel technology for cost-effective $\mathrm{CO}_{2}$ enhanced oil recovery. Society of Petroleum Engineers, 2012.

[19] Mogbo O.: $\mathrm{CO}_{2}$ EOR and sequestration in a depleted gas-condensate reservoir UKNS case study. Society of Petroleum Engineers, 2011.

[20] Nguyen D.N.: Carbon dioxide geological sequestration: Technical and economic reviews. Society of Petroleum Engineers, 2003.

[21] Ogden J., Johnson N.: Techno-economic analysis and modeling of carbon dioxide $\mathrm{CO}_{2}$ capture and storage CCS technologies, University of California, 2011.

[22] Stopa J., Kosowski P.: Wptyw sekwestracji geologicznej na koszty wytwarzania energii w elektrowniach weglowych i gazowych. Polityka Energetyczna, 2005. 
[23] Stopa J., Wojnarowski P., Kosowski P.: Prognoza efektywności ekonomicznej sekwestracji $\mathrm{CO}_{2} \mathrm{w}$ złożu ropy naftowej. Polityka Energetyczna, 2005.

[24] Sucholska K., Bezpieczeństwo geologicznej sekwestracji $\mathrm{CO}_{2}-$ zagrożenia i prewencja. Górnictwo i Geologia, 2012.

[25] Tarkowski R.: Geologiczna sekwestracja $\mathrm{CO}_{2}$. Wydawnictwo Instytutu Gospodarki Surowcami Mineralnymi i Energią PAN, 2005.

[26] Tarkowski R., Uliasz-Misiak B.: Podziemne składowanie - sposób na dwutlenek węgla. Przegląd Geologiczny, 2007.

[27] Torvanger A., Rypdal K., Kallbekken S.: Geological $\mathrm{CO}_{2}$ storage as a climate change mitigation option. Springer, 2004.

[28] Uliasz-Bocheńczyk A., Mokrzycki E.: Przegląd możliwości utylizacji ditlenku węgla. Wiertnictwo Nafta Gaz, 2005. 